\title{
AN AIRCRAFT ENCOUNTER WITH TURBULENCE IN THE VICINITY OF A THUNDERSTORM
}

\author{
David W. Hamilton* and Fred H. Proctor ${ }^{\dagger}$ \\ NASA Langley Research Center \\ Hampton, Virginia
}

\begin{abstract}
$\underline{\text { Abstract }}$
Large eddy simulations of three convective turbulence events are investigated and compared with observational data. Two events were characterized with severe turbulence and the other with moderate turbulence. Two of the events occurred during NASA's turbulence flight experiments during the spring of 2002, and the third was an event identified by the Flight Operational Quality Assurance (FOQA) Program. Each event was associated with developing or ongoing convection and was characterized by regions of low to moderate radar reflectivity. Model comparisons with observations are favorable. The data sets from these simulations can be used to test turbulence detection sensors.
\end{abstract}

\section{$\underline{\text { Introduction }}$}

Commercial aircraft encounters with unexpected turbulence may lead to injuries and fatalities, especially among unsecured passengers and crew members. Therefore, the National Aeronautics and Space Administration (NASA), through its Aviation Safety Program, is addressing turbulence hazards through research, flight experiments, and data analysis. Recently, an initial flight campaign, that used NASA-Langley's B757, has tested a Turbulence Prediction And Warning System (TPAWS). 1,2,3,4

Aircraft encounters with turbulence may occur within either clear air or clouds. Turbulence associated with convective clouds, otherwise known as Convectively Induced Turbulence (CIT), is a leading hazard to aviation operations. Approximately $82 \%$ of turbulence encounters that lead to injuries are in proximity to atmospheric convection. ${ }^{5}$ Although aircraft attempt to avoid flying

*Research Scientist, Airborne Systems Competency

${ }^{\dagger}$ Research Scientist, Airborne Systems Competency, AIAA member

This material is a work of the U.S. Government and is not subject to copyright protection in the United States. directly into the path of thunderstorms, unsuspecting encounters with CIT continue to occur. These encounters may occur as aircraft: 1) try to skirt around the high reflectivity regions of storms in order to minimize the deviation from their planned route, 2) encounter unexpected convection that appears to be invisible or benign from the aircraft's radar, 3) encounter storm tops that rapidly rise into the aircraft's flight path, and 4) are inadvertently vectored into convection by Air Traffic Control (ATC). In some cases of CIT, the ship's conventional radar, which is the pilot's only onboard tool for severe weather avoidance, may not detect any radar reflectivity signature. TPAWS is designed to provide enhanced CIT avoidance, even in these regions of minimal radar reflectivity.

A second flight campaign to demonstrate the feasibility of TPAWS to detect CIT was conducted in the spring of 2002. TPAWS is centered on the development of radar algorithms that produce a reliable turbulence alert of an acceptable time prior to a hazardous encounter. These algorithms process standard airborne radar data to make predictions, thus requiring no hardware modifications to aircraft. Analysis of the radar performance during the second campaign is promising. Of 49 encounters with moderate to severe turbulence, $81 \%$ of the events were predicted 30 seconds or more prior to encounter. ${ }^{6}$

Turbulence detection software must be certified by the FAA before being installed into the commercial fleet. A major goal of the TPAWS project element is to support this certification process. This includes developing a 'tool set' consisting of atmospheric turbulence data sets, hazard estimation models, aircraft performance models, and radar simulation software, which used together will establish statistically viable radar performance. Hence, NASA's role will be to provide tools and procedures to assist in the evaluation of an operational system that will result in minimal missed detections and false alerts.

Presented in this paper will be data sets produced from large eddy simulations of three CIT encounter environments. Also examined are a hazard estimation model and a simple aircraft performance model. The hazard estimation model enables predictions of turbulence loads based on the vertical wind field, and is 


\section{Correlation of Peak Load With Peak RMS Load ( $5 \mathrm{sec}$. window)}

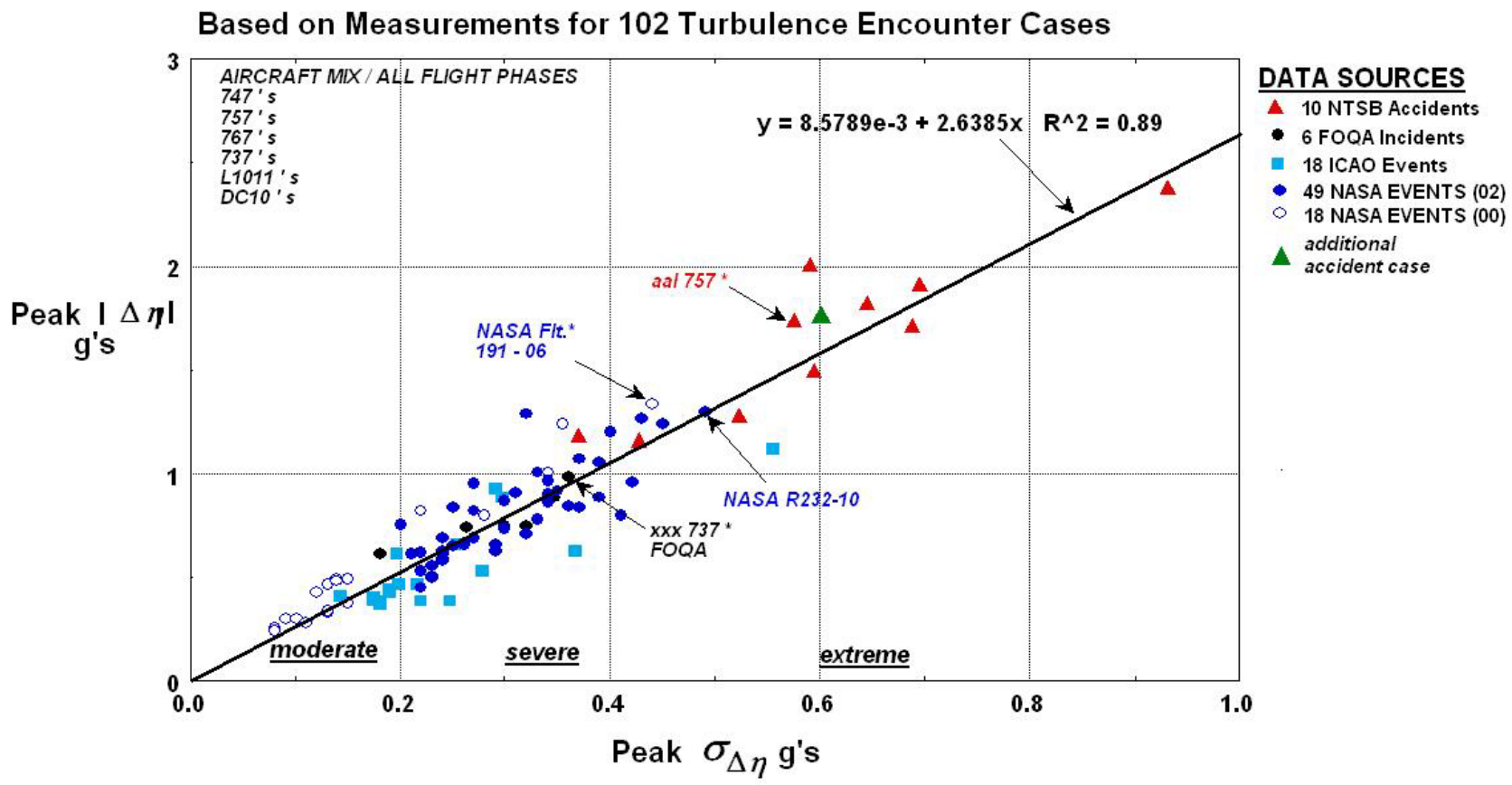

ESTIMATED FROM RADAR OBSERVABLES FOR TPAWS CONCEPT

Figure 1. Comparison of the peak load $(\Delta n)$ to the computed 5 second variance of the peak load $\left(\sigma_{\Delta n}\right)$ for 102 turbulence encounter cases (Bowles) ${ }^{6}$.

flight path independent. The output from this product can determine regions where turbulence would be a hazard to aircraft operations, and will be useful to compare with radar simulations that utilized the convective turbulence data sets. The aircraft performance model is an additional tool that can be used to compare with the hazard estimation and radar simulated predicted loads. Both models are verified with NASA flight in situ data and applied to the simulation data sets. Also, groundbased Weather Surveillance Radar - 1988 Doppler $(\mathrm{NEXRAD})^{7}$ radar data is examined in order to support the verification of the simulated data sets.

\section{Definitions}

Quantification of the turbulence hazard must be related to the aircraft response, and should have properties that can be estimated by onboard detection sensors. Metrics for defining the turbulence hazard can be quantified in terms of RMS normal loads $\left(\sigma_{\Delta n}\right)$, where $\sigma_{\Delta \mathrm{n}}$ is based on moving 5-second intervals of aircraft normal loads $(\Delta \mathrm{n}){ }^{1,2}$ Using this metric, moderate turbulence is defined for: $0.20 \mathrm{~g} \leq \sigma_{\Delta \mathrm{n}}<0.30 \mathrm{~g}$, and severe when $\sigma_{\Delta \mathrm{n}} \geq 0.30 \mathrm{~g}$. Bowles ${ }^{6}$ has shown that the peak aircraft normal loads, are roughly proportional to $\sigma_{\Delta \mathrm{n}}$, as shown in Figure 1. In no event did $|\Delta \mathrm{n}|$ ever exceed $1 \mathrm{~g}$ when $\sigma_{\Delta \mathrm{n}}<0.30 \mathrm{~g}$. On the other hand, peak loads may exceed $1 g$ in the severe turbulence category; thus, turbulence encounter intensities with $\sigma_{\Delta \mathrm{n}}>0.30 \mathrm{~g}$ may cause passengers and obstacles in the cabin to become weightless, an obviously dangerous situation. Therefore, a 'Must Alert' criteria has been proposed when the operational turbulence detection system predicts an event with $\sigma_{\Delta \mathrm{n}} \geq 0.30 \mathrm{~g}$. Also a 'May Alert' region is proposed for $0.20 \mathrm{~g} \leq \sigma_{\Delta \mathrm{n}}<0.30 \mathrm{~g}$, which would provide a buffer that would ensure the minimizing of false alerts.

\section{$\underline{\text { Turbulence Data Sets }}$}

Characterization of the turbulence associated with CIT events is critical to the development of new technology that would warn for such events. Furthermore, these characterizations are critical when producing data sets required for the 'tool set' that will be applied in the certification process. Therefore, three particular events of interest, two events from NASA's 2002 Flight Tests (Events: 235_05 and 232_10), along 
with a FOQA ${ }^{*}$ case of severe turbulence encounter that occurred near Wilmington, DE are investigated. Presented here are discussions of each encounter and the corresponding results from large eddy simulations (LES).

\section{Numerical Model and Initial Conditions}

The numerical model employed for this study is the Terminal Area Simulation System (TASS). TASS is an LES model with a meteorological framework, and has been used in previous studies to examine a wide variety of weather/fluid mechanics problems such as microburst, wind shear, wake vortices, and turbulence. A description of TASS is located in Proctor, Hamilton, and Bowles. ${ }^{2}$

In order to simulate the convective turbulence environments encountered during each of the three events, appropriate initial conditions must be chosen. In TASS, each convective event is generated via initialization with the wind velocity, temperature, and humidity that represents the ambient conditions of that case. Turbulence, at scales important to aircraft response, is generated by the dynamic interaction of the convective cells and ambient winds. Localized regions of turbulence are produced by TASS with realistic intensities and accompanying radar reflectivity. Output from the model includes three-dimensional data sets of wind fields, radar reflectivity, moisture, and temperature.

\section{NASA Event 235-05}

\section{Observation}

The first event to be presented occurred during the second NASA TPAWS flight campaign, which was conducted during April and May of 2002. Details of the aircraft sensors, flight preparations, and flight requirements/restrictions are available in Hamilton and Proctor. ${ }^{1}$

This case occurred on May 10, 2002, when the NASA B757 encountered turbulence over Charleston, SC (Figure 2). During event 235_05, moderate turbulence was encountered in nearly cloudless air just above a rapidly developing thunderstorm. Radar reflectivity was up to $44 d B Z$ near the flight path but detectable values were never penetrated. In fact, the aircraft maintained visual meteorological conditions throughout the event, skimming what appeared to be light cloud debris for about a 2 second period. Along the flight path, no radar reflectivity signatures appeared on the ship's

\footnotetext{
* Flight Operational Quality Assurance (FOQA) Programs are an attempt by airlines to identify data from potentially unsafe but otherwise uneventful airline flights in order to correct potential problems before they lead to accidents.
}

convectional radar, which is purportedly the case in many CIT encounter accidents. A data set from the numerical simulation of this event could be useful in evaluating TPAWS alerting rules, since turbulence may not be detected along the flight path due to weak radar reflectivity, but may be seen nearby where higher levels of radar reflectivity exist.

The convection that produced the turbulence environment was developing along a westward propagating sea-breeze front oriented parallel to the Atlantic coastline. A number of cells had developed along the sea breeze with storm tops between 6 and $8 \mathrm{~km}$. The cells were pulsing along the front and dissipating as they drifted slowly to the southeast over the relatively cooler sea-breeze airmass. Horizontal winds at flight level (6.5 km Above Ground Level (AGL)) were weakly sheared and storm tops ranged between 6 and $8 \mathrm{~km}$.

The NASA B757 maintained visual meteorological conditions (VMC) throughout the event. At 19:20:39 UTC, the aircraft passed a relatively high reflectivity (44 $d B Z$ ) region approximately $2 \mathrm{~km}$ off the aircraft's starboard side. Nine seconds later the aircraft experienced a peak updraft of $11 \mathrm{~m} \mathrm{~s}^{-1}$ in relatively clear air, although some cloud debris surrounded the aircraft (Figure 3). Airborne radar suggested radar reflectivity levels to be between 16-20 dBZ about $120 \mathrm{~m}$ below the

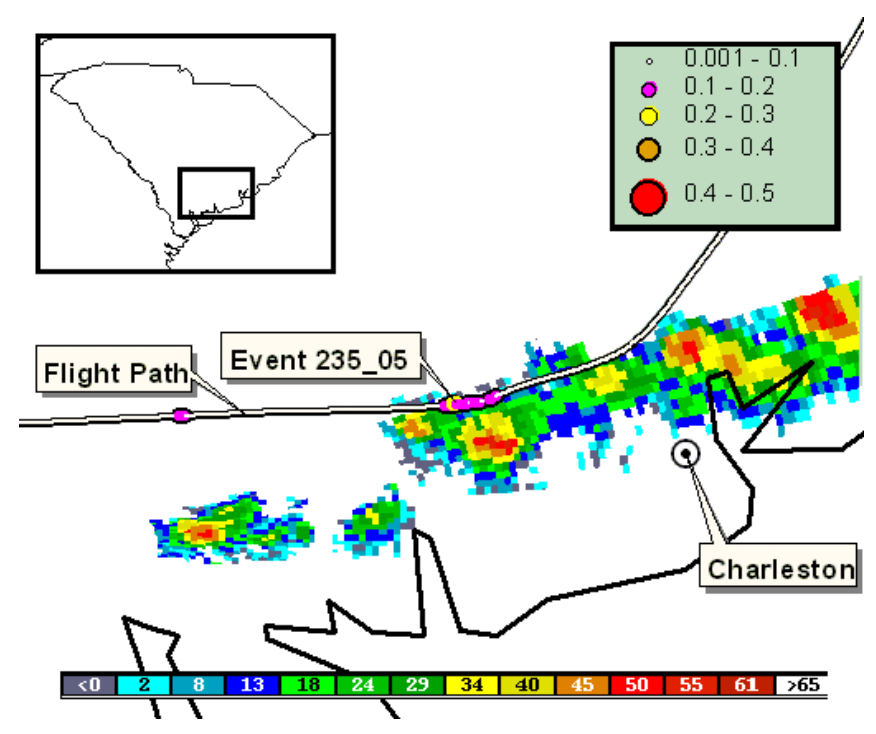

Figure 2. Composite ${ }^{\dagger}$ radar reflectivity (dBZ) and flight path with in situ RMS normal loads ( $g$ 's) along path for Event 235_05.

$\dagger$ Composite radar reflectivity is a display of the maximum reflectivity from any elevation angle at every range from the radar. This product is used to reveal the maximum reflectivity above any location. 
flight path but no apparent reflectivity at the flight path altitude. The peak normal loads $(\Delta \mathrm{n})$ associated with the updraft region were +0.43 and $-0.38 g$ and $\sigma_{\Delta n}$ peaked at $0.22 \mathrm{~g}$ at approximately 19:20:50 UTC (Figure 4). The aircraft continued to experience successive positive and negative normal loads $(\Delta \mathrm{n})$ due to a series of updrafts and downdrafts in the clear air regions at the lee of the cloud.

\section{Numerical Simulation}

The simulation for this case included a domain size of $20 \mathrm{~km} \times 20 \mathrm{~km} \times 12 \mathrm{~km}$. The total number of grid points in the domain is $206 \times 206 \times 130$, with a uniform grid size of $100 \mathrm{~m}$ above a stretched boundary layer region. The initial environmental conditions were taken from the Charleston rawinsonde observation at 0000 UTC on 11 May, 2002. The boundary layer for the input conditions was modified using Automated Surface Observation System (ASOS) data taken from Charleston one hour prior to the encounter.

A brief comparison of the simulated and observed convective characteristics is shown in Table 1. A threedimensional perspective of the convective cell is shown in Figure 5. Figure 6 shows the simulated radar reflectivity at $7.4 \mathrm{~km}$, which compares well with radar signatures observed by the Charleston, SC NEXRAD radar shown in Figure 7. An altitude of $7.4 \mathrm{~km}$ was chosen because it had better characteristics with the observed event. This is about $900 \mathrm{~m}$ above the actual flight path.

Table 1: Comparison of simulated and observed characteristics for Event 235_05.

\begin{tabular}{|c|c|c|c|c|}
\hline Variable & \multicolumn{2}{|c|}{ TASS } & \multicolumn{2}{|c|}{ Observed } \\
\hline Peak Storm Tops & \multicolumn{2}{|c|}{$8 \mathrm{~km}$} & \multicolumn{2}{|c|}{$6-8 \mathrm{~km}$} \\
\hline $\begin{array}{c}\text { Peak Radar } \\
\text { Reflectivity near } \\
\text { Flight Level }\end{array}$ & \multicolumn{2}{|c|}{$45 d B Z$} & \multicolumn{2}{|c|}{$44 d B Z$} \\
\hline Cell Motion (toward) & \multicolumn{2}{|c|}{$\begin{array}{l}\text { ESE at } \\
8.7 \mathrm{~m} \mathrm{~s}^{-1}\end{array}$} & \multicolumn{2}{|c|}{$\begin{array}{l}\text { ESE at } \\
5.3 \mathrm{~m} \mathrm{~s}^{-1}\end{array}$} \\
\hline $\begin{array}{c}\text { Diameter of } \\
\text { Convective Cell } \\
\text { (based on } 20 \mathrm{dBZ} \text { ) }\end{array}$ & \multicolumn{2}{|c|}{$\begin{array}{c}3.5 \mathrm{~km} \\
\text { at } z=6 \mathrm{~km}\end{array}$} & \multicolumn{2}{|c|}{$\begin{array}{c}4 \mathrm{~km} \\
\text { at } z=6 \mathrm{~km}\end{array}$} \\
\hline $\begin{array}{c}\text { Peak Vertical } \\
\text { Velocity near Flight } \\
\text { Level }\end{array}$ & $\begin{array}{c}\operatorname{Max} \\
10 \\
m s^{-1}\end{array}$ & $\begin{array}{c}\text { Min } \\
-6 \\
m s^{-1}\end{array}$ & $\begin{array}{c}\operatorname{Max} \\
11 \\
m s^{-1}\end{array}$ & $\begin{array}{c}\text { Min } \\
-4 \\
m s^{-1}\end{array}$ \\
\hline $\begin{array}{l}\text { Horizontal Scale of } \\
\text { Turbulence Patch at } \\
\text { Flight Level }\end{array}$ & \multicolumn{2}{|c|}{$3 \mathrm{~km}$} & \multicolumn{2}{|c|}{$3 \mathrm{~km}$} \\
\hline $\begin{array}{c}\text { Peak } \sigma_{\Delta \mathrm{n}} \text { at Flight } \\
\text { Level }\end{array}$ & \multicolumn{2}{|c|}{$0.26 \mathrm{~g} *$} & \multicolumn{2}{|c|}{$0.22 \mathrm{~g}$} \\
\hline
\end{tabular}

* from Hazard Estimation Model

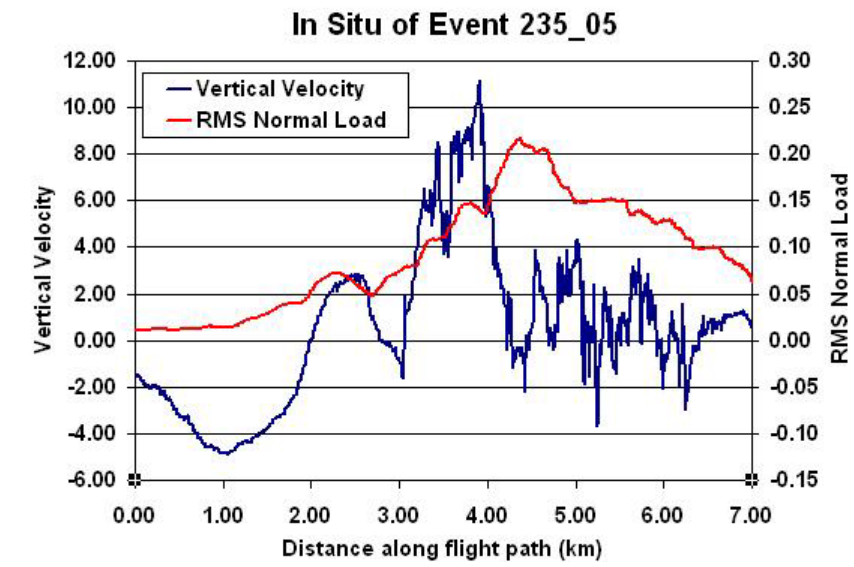

Figure 3. In situ vertical velocity $\left(\mathrm{m} \mathrm{s}^{-1}\right)$ and $\sigma_{\Delta n}(\mathrm{~g}$ 's) along path for Event 235_05.

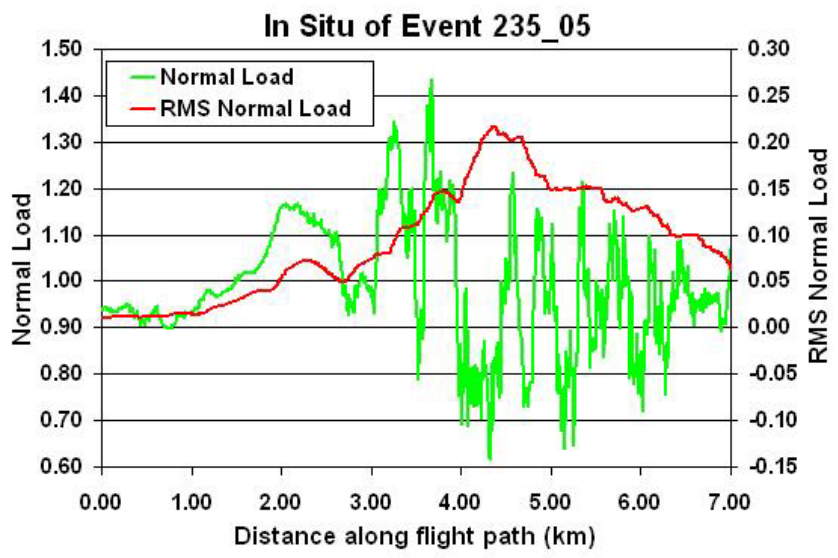

Figure 4. In situ $\Delta n\left(g\right.$ 's) and $\sigma_{\Delta n}(g$ 's) along path for Event 235_05.

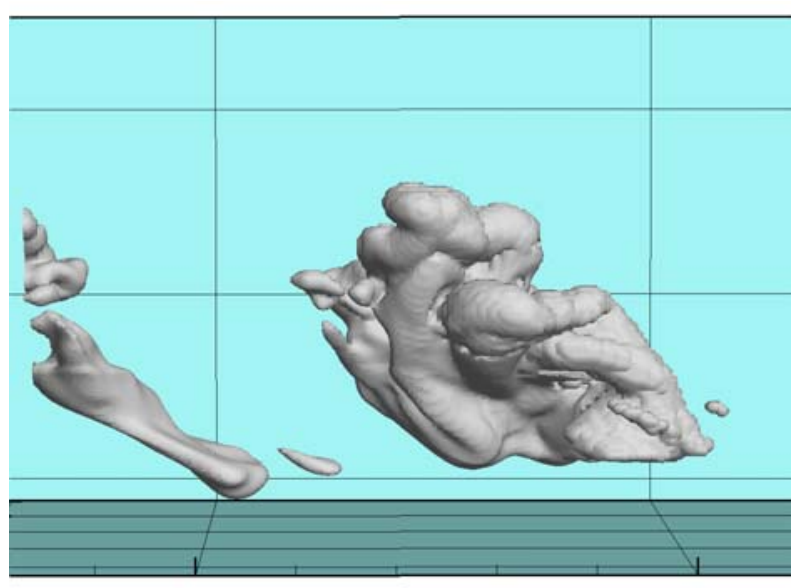

Figure 5. Three-dimensional perspective of TASS simulated cloud for Event 235_05. 


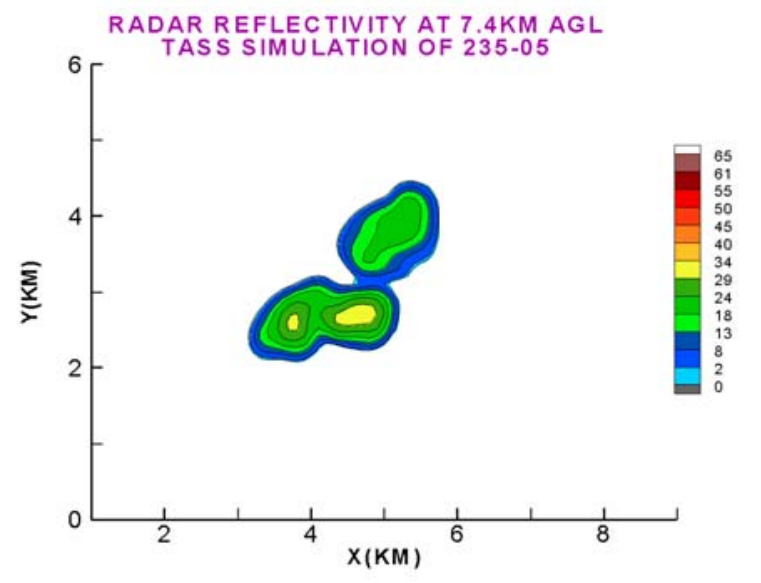

Figure 6. TASS simulated radar reflectivity (dBZ) for Event 235_05.

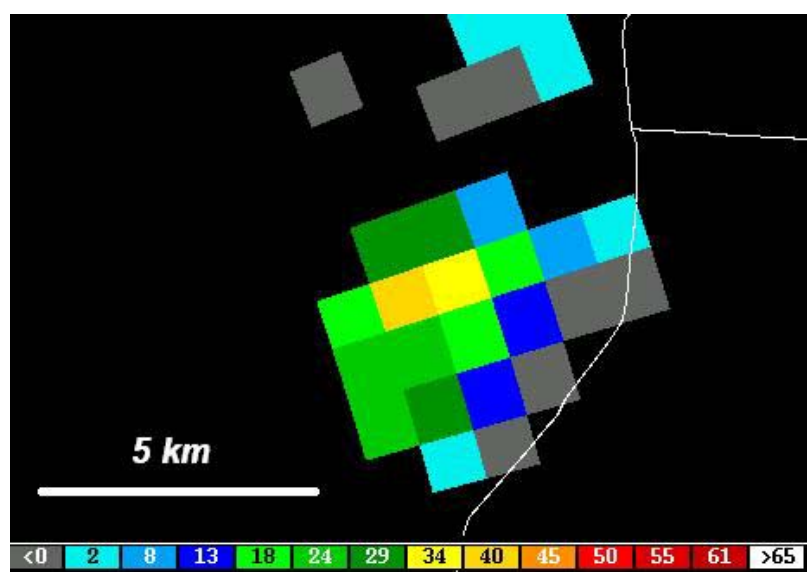

Figure 7. Charleston, SC NEXRAD imagery observed near flight path for Event 235_05.

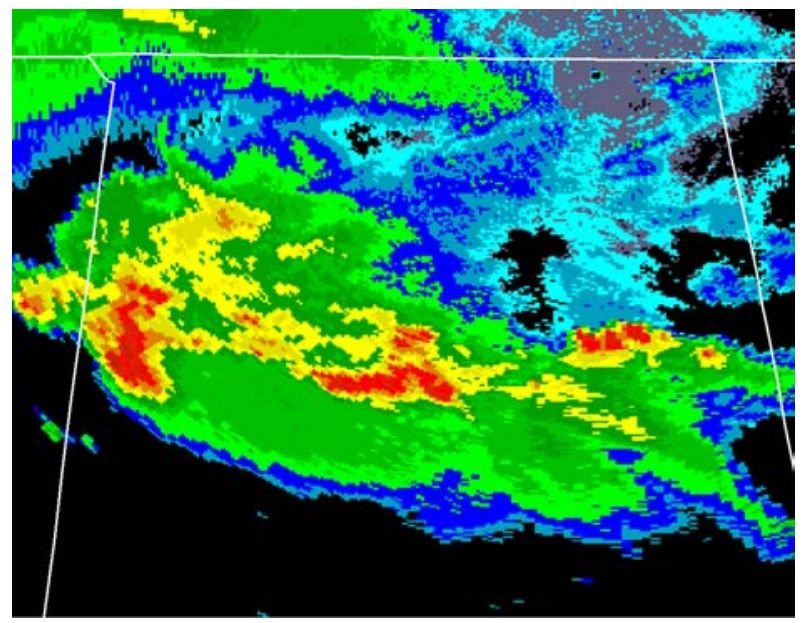

Figure 8. Huntsville, AL composite radar reflectivity for Event 232_10. Color table for reflectivity levels are same as in Figure 2.

\section{$\underline{R 232 \quad 10}$}

\section{Observation}

The second case occurred on 30 April 2002. In this event, the NASA B757 was vectored to central Alabama to investigate turbulence regions associated with a large thunderstorm complex. ${ }^{6}$ Composite radar reflectivity from the Huntsville, AL, NEXRAD shows a line of convective cells that extended east to west across Alabama (Figure 8). Storm tops were between 10 and 12 $\mathrm{km}(35,000$ and 40,000 ft) and cell motion was towards the east-southeast at $40 \mathrm{~m} \mathrm{~s}^{-1}$. Ambient winds at flight level, $10.5 \mathrm{~km}$ AGL, were from the west-northwest at 50 $m s^{-1}$ (100 kts), with significant vertical shear near the upper portions of the storm. An airmet for moderate turbulence had been issued indicating wide-spread turbulence in association with the vertical wind shear at the jet stream levels. The prevailing operational situation was an environment that precluded 'see and avoid' options for the pilots, which was the case for much of the region. At the flight level, low levels of radar reflectivity were present, often presenting no reflectivity signatures on the conventional ships radar-display. The characteristics of this event and the general operational hazards due to CIT are signified by the encountering of severe turbulence by two commercial air carriers in the vicinity of Event 232_10 (Figure 9).

\section{Numerical Simulation}

The domain size for this case is $20 \mathrm{~km} \times 30 \mathrm{~km} \times$ $14.75 \mathrm{~km}$, with periodic conditions assumed on the eastern and western edges of the grid. The number of grid points in the domain is $254 \times 378 \times 178$, with a horizontal grid spacing of $80 \mathrm{~m}$. The vertical grid size stretches with height. The domain is rotated 12 degrees clockwise. The initial environmental conditions were extracted from the Mesoscale Analysis and Prediction System (MAPS) forecast near time and location of event. MAPS is the experimental version of the Rapid Update Cycle. $^{8}$

Comparisons between the observed and simulated environments for Event 232-10 are presented in Table 2. The simulated radar reflectivity field is shown in Figure 10 and compares well with the observed radar reflectivity in Figure 9.

The TASS simulation indicates overshooting tops with strong horizontal gradients of vertical velocity (Figure 11). Associated with these overshooting tops are regions of very weak radar reflectivity (Figure 10). 


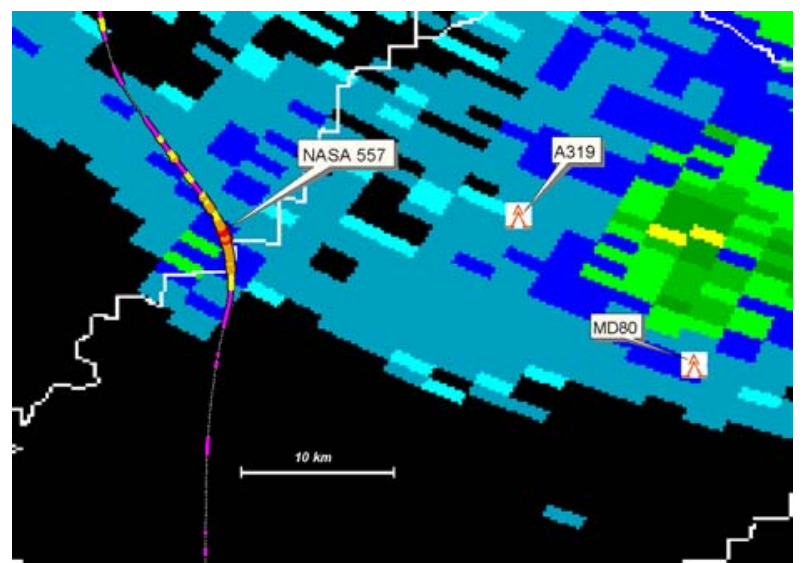

Figure 9. Flight path for Event 232_10. Color tables for reflectivity levels and aircraft RMS normal loads $\left(\sigma_{\Delta n}\right)$ along path are same as in Figure 2. Also denoted are two severe turbulence pilot reports that occurred within 30 minutes of the event.

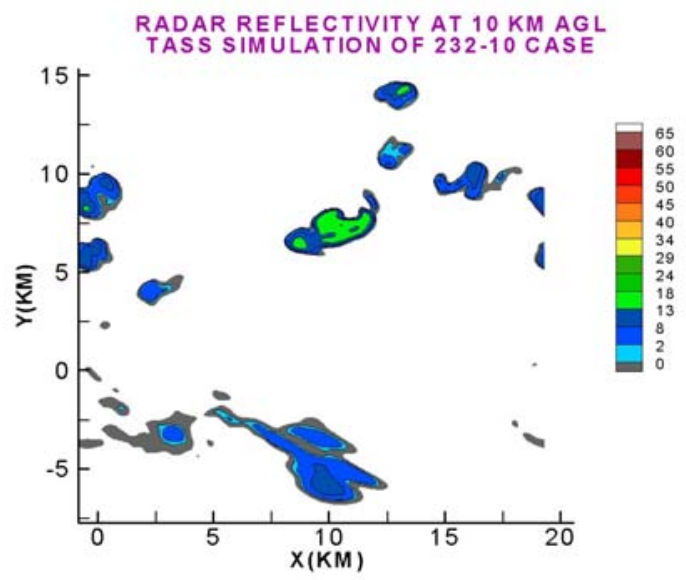

Figure 10. Same as in Figure 6, but for Event 232_10.

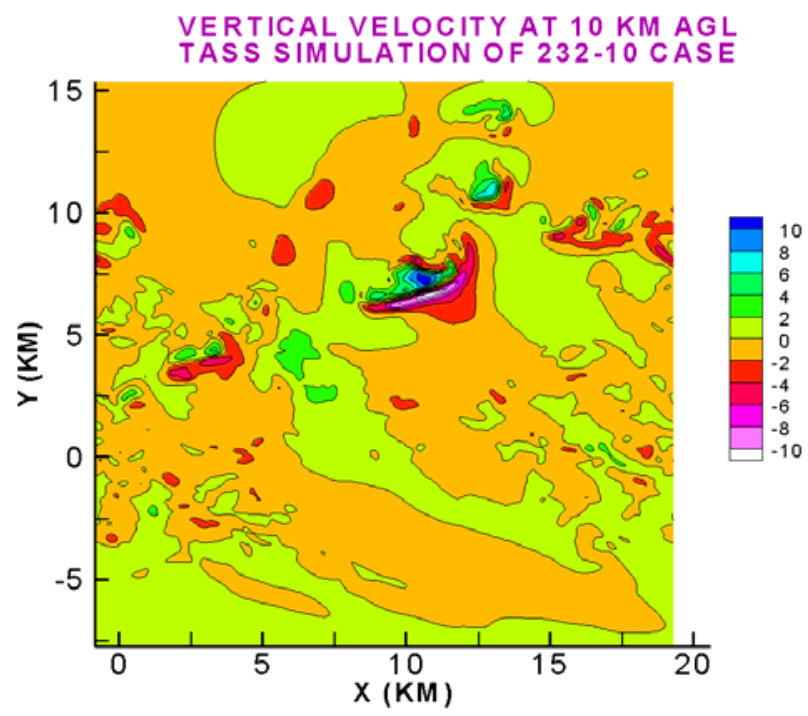

Figure 11. TASS simulated vertical velocity $\left(\mathrm{m} \mathrm{s}^{-1}\right)$ for Event 232_10.
Table 2: Comparison of simulated and observed characteristics for Event 232_10.

\begin{tabular}{|c|c|c|c|c|}
\hline Variable & \multicolumn{2}{|c|}{ TASS } & \multicolumn{2}{|c|}{ Observed } \\
\hline Peak Storm Tops & \multicolumn{2}{|c|}{$11 \mathrm{~km}$} & \multicolumn{2}{|c|}{$10-12 \mathrm{~km}$} \\
\hline $\begin{array}{c}\text { Peak Radar } \\
\text { Reflectivity near } \\
\text { Flight Level }\end{array}$ & \multicolumn{2}{|c|}{$17.5 \mathrm{dBZ}$} & \multicolumn{2}{|c|}{$\begin{array}{c}18 \mathrm{dBZ} \\
\text { from aircraft }\end{array}$} \\
\hline $\begin{array}{c}\text { Cell Motion } \\
\text { (toward) }\end{array}$ & \multicolumn{2}{|c|}{$\begin{array}{l}\text { ESE at } \\
35 \mathrm{~ms}^{-1}\end{array}$} & \multicolumn{2}{|c|}{$\begin{array}{l}\text { ESE at } \\
40 \mathrm{~ms}^{-1}\end{array}$} \\
\hline $\begin{array}{l}\text { Width of Convective } \\
\text { Line near Ground } \\
\text { (based on } 20 \mathrm{dBZ} \text { ) }\end{array}$ & \multicolumn{2}{|c|}{$11 \mathrm{~km}$} & \multicolumn{2}{|c|}{$15-25 \mathrm{~km}$} \\
\hline $\begin{array}{c}\text { Peak Vertical } \\
\text { Velocity near Flight } \\
\text { Level }\end{array}$ & $\begin{array}{c}\operatorname{Max} \\
11 \\
m s^{-1}\end{array}$ & $\begin{array}{l}\text { Min } \\
-11 \\
m s^{-1}\end{array}$ & $\begin{array}{c}\operatorname{Max} \\
15 \\
m s^{-1}\end{array}$ & $\begin{array}{l}\text { Min } \\
-21 \\
m s^{-1}\end{array}$ \\
\hline $\begin{array}{l}\text { Horizontal Scale of } \\
\text { Turbulence Patch } \\
\text { near Flight Level }\end{array}$ & \multicolumn{2}{|c|}{$3-5 \mathrm{~km}$} & \multicolumn{2}{|c|}{$8 \mathrm{~km}$} \\
\hline $\begin{array}{c}\text { Peak } \sigma_{\Delta \mathrm{n}} \text { near Flight } \\
\text { Level }\end{array}$ & \multicolumn{2}{|c|}{$0.38 g^{*}$} & \multicolumn{2}{|c|}{$0.45 g$} \\
\hline
\end{tabular}

* from Hazard Estimation Model

\section{Wilmington, Delaware FOQA case}

\section{Observation}

The last case is a FOQA event in which a commercial B-737 encountered a line of shallow convection on descent. An analysis of this event was documented by MIT Lincoln Laboratory. ${ }^{9}$

The airliner encountered severe turbulence on descent as it was vectored by ATC along a convective line. This event was a relatively low altitude case occurring at an altitude of $2.3 \mathrm{~km}$. The turbulence encounter occurred as the airliner penetrated the leading edge (southeastern side) of a line of relatively shallow convective precipitation.

\section{Numerical Simulation}

The initial environmental conditions for this simulation were extracted from a Mesoscale Atmospheric Simulation System (MASS) ${ }^{10}$ forecast near the time and location of the event. The domain size for this simulation is $14 \mathrm{~km} \times 7.5 \mathrm{~km} \times 6.25 \mathrm{~km}$, with periodic conditions chosen on the lateral boundaries that are orthogonal to the convective line. The number of grid points in the domain is $283 \times 154 \times 128$, with a uniform grid size of $50 \mathrm{~m}$. The domain is rotated 245 degrees clockwise. 
Table 3: Comparison of simulated and observed characteristics for Delaware FOQA case.

\begin{tabular}{|c|c|c|c|c|}
\hline Variable & \multicolumn{2}{|c|}{ TASS } & \multicolumn{2}{|c|}{ Observed } \\
\hline Peak Storm Tops & \multicolumn{2}{|c|}{$5.25 \mathrm{~km}$} & \multicolumn{2}{|c|}{$5.5-7.6 \mathrm{~km}$} \\
\hline $\begin{array}{c}\text { Peak Radar } \\
\text { Reflectivity near } \\
\text { Flight Level }\end{array}$ & \multicolumn{2}{|c|}{$46 d B Z$} & \multicolumn{2}{|c|}{$\begin{array}{c}40 \mathrm{dBZ} \\
\text { from } N E X R A D\end{array}$} \\
\hline Cell Motion (toward) & \multicolumn{2}{|c|}{$\begin{array}{c}\mathrm{SE} \\
\text { at } 25 \mathrm{~ms}^{-1}\end{array}$} & \multicolumn{2}{|c|}{$\begin{array}{c}\text { SE } \\
\text { at } 20 \mathrm{~m} \mathrm{~s}^{-1}\end{array}$} \\
\hline $\begin{array}{l}\text { Width of Convective } \\
\text { Line near Ground } \\
\text { (based on } 20 d B Z \text { ) }\end{array}$ & \multicolumn{2}{|c|}{$9 \mathrm{~km}$} & \multicolumn{2}{|c|}{$10-18 \mathrm{~km}$} \\
\hline $\begin{array}{c}\text { Peak Vertical } \\
\text { Velocity near Flight } \\
\text { Level } \\
\end{array}$ & $\begin{array}{c}\text { Max } \\
12 \\
m s^{-1}\end{array}$ & $\begin{array}{l}\text { Min } \\
-10 \\
m s^{-1}\end{array}$ & $\begin{array}{c}\operatorname{Max} \\
14 \\
m s^{-1}\end{array}$ & $\begin{array}{c}\text { Min } \\
-14 \\
m s^{-1}\end{array}$ \\
\hline $\begin{array}{c}\text { Peak } \sigma_{\Delta \mathrm{n}} \text { near Flight } \\
\text { Level }\end{array}$ & \multicolumn{2}{|c|}{$0.33 \mathrm{~g} *$} & \multicolumn{2}{|c|}{$0.36 \mathrm{~g}$} \\
\hline $\begin{array}{l}\text { Propagation speed of } \\
\text { convective line }\end{array}$ & \multicolumn{2}{|c|}{$13 m s^{-1}$} & \multicolumn{2}{|c|}{ 6-19 $\mathrm{ms}^{-1}$} \\
\hline
\end{tabular}

* from Hazard Estimation Model

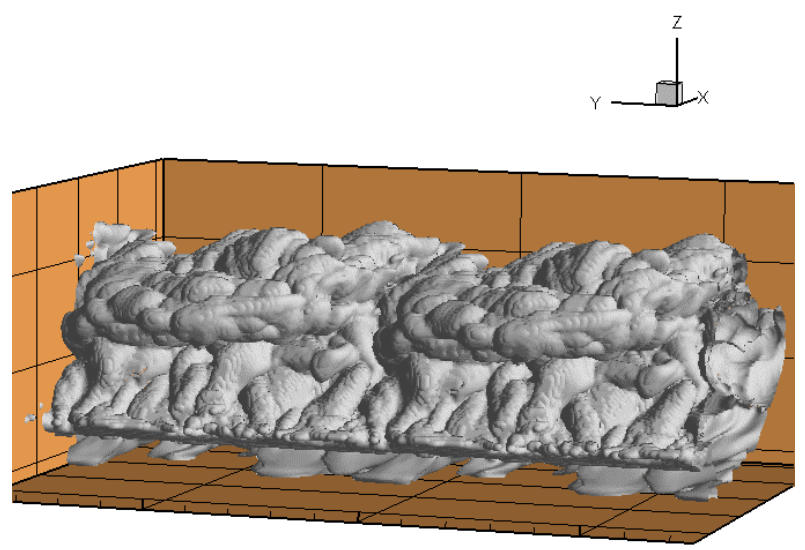

Figure 12. Same as in Figure 5 but for the FOQA case.

Comparisons between the simulated and observed environment are shown in Table 3. A three-dimensional perspective of the convective line is shown in Figure 12. The simulated radar reflectivity field at flight level for the FOQA case is presented in Figure 13. Peak radar reflectivity barely exceeds $40 \mathrm{dBZ}$ as was true from the observed NEXRAD images presented by Ferris. ${ }^{9}$ The associated vertical motion field (Figure 14)exhibits a pattern of significant updrafts and downdrafts along the convective line. The strongest vertical velocities are located on the forward side of the line and coincide with areas of relatively low radar reflectivity $(<30 \mathrm{dBZ})$.

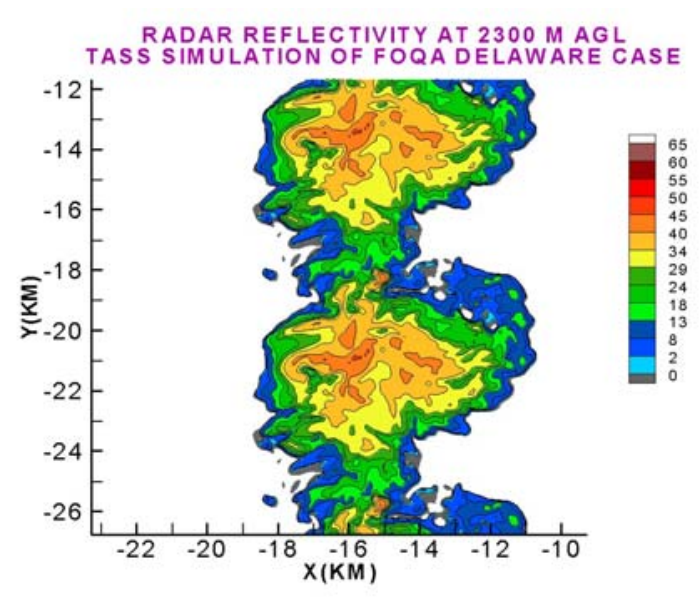

Figure 13. Same as in Figure 6, but for FOQA case.

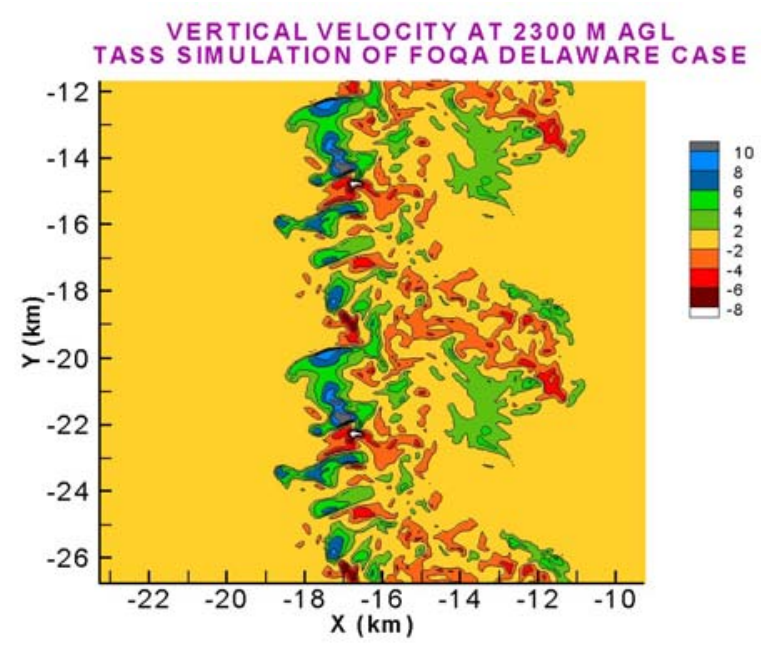

Figure 14. Same as in Figure 11 but for FOQA case.

\section{$\underline{\text { Hazard Analyses }}$}

The turbulence hazard is quantified for the previous case studies by applying hazard estimation 'tools.'

\section{Hazard Estimation Model}

As in Proctor et al. ${ }^{2}$, we apply hazard metric algorithms to the simulated data sets.

For a particular aircraft, $\sigma_{\Delta \mathrm{n}}$ can be estimated from $\sigma_{\mathrm{w}}$ using aircraft look-up tables. ${ }^{11}$ The $\sigma_{\mathrm{w}}$ fields can be computed for any horizontal plane in the each data set, by using a moving average as:

$$
\begin{aligned}
& \sigma_{w}(x, y)= \\
& {\left[\frac{1}{L_{x} L_{y}} \int_{x-\frac{L_{x}}{2}}^{x+\frac{L_{x}}{2}} \int_{y-\frac{L_{y}}{2}}^{y+\frac{L_{y}}{2}}\left\{w\left(x^{\prime}, y^{\prime}\right)-\bar{w}(x, y)\right\}^{2} d x^{\prime} d y^{\prime}\right]^{\frac{1}{2}}}
\end{aligned}
$$


where the averaging interval along the $x$ and $y$ coordinates is $L_{x}, L_{y}$, respectively. The average vertical

wind, $\bar{w}$, is computed from the vertical wind, $w$, as:

$$
\bar{w}(x, y)=\frac{1}{L_{x} L_{y}} \int_{x-\frac{L_{x}}{2}}^{x+\frac{L_{x}}{2}} \int_{y-\frac{L_{y}}{2}}^{y+\frac{L_{y}}{2}} w\left(x^{\prime}, y^{\prime}\right) d x^{\prime} d y^{\prime}
$$

The value for the averaging interval, $L_{x}=L_{y}=1000$ $m$, is chosen to correspond to $\sim 5 s$ averaging period for a commercial aircraft at cruise speeds. Hence, the second moment of the $w$-field is computed assuming a $1 \times 1 \mathrm{~km}$ moving box. At slower speeds (such as during descent) a smaller averaging interval for $L_{x}$ and $L_{y}$ is assumed that corresponds to the shorter distance traveled by the aircraft in $5 s$. Using formulas developed by Bowles, the RMS normal load can be estimated from $\sigma_{\mathrm{w}}$ for NASA's B-757 by:

$$
\begin{aligned}
& \sigma_{\Delta n}(x, y)=\sigma_{w}(x, y)[a(z)-b(z) \log (l)] \\
& *\left(\frac{180}{W_{a}}\right)\left(\frac{V}{V n(z)}\right) * K
\end{aligned}
$$

where $V$ is aircraft's true airspeed, $W_{a}$ is the aircraft weight in kilo-pounds, $K=1.09$, and the turbulence length scale $l \equiv 500 \mathrm{~m}$. The parameters $a(z), b(z)$, and $V_{n}(z)$ are:

$$
\mathrm{a}(\mathrm{z})=c_{1}+c_{2} z+c_{3} z^{2}+c_{4} z^{3}+c_{5} z^{4}+c_{6} z^{5}+c_{7} z^{6}
$$

where:

$$
\begin{aligned}
& c_{1}=0.136700 \mathrm{~s}-1 \\
& c_{2}=-4.759443 \mathrm{e}-05 \mathrm{~m}^{-1} \mathrm{~s}^{-1} \\
& c_{3}=3.453818 \mathrm{e}-08 \mathrm{~m}^{-2} \mathrm{~s}^{-1} \\
& c_{4}=-1.031272 \mathrm{e}-11 \mathrm{~m}^{-3} \mathrm{~s}^{-1} \\
& c_{5}=1.457209 \mathrm{e}-15 \mathrm{~m}^{-4} \mathrm{~s}^{-1} \\
& c_{6}=-9.709422 \mathrm{e}-20 \mathrm{~m}^{-5} \mathrm{~s}^{-1} \\
& c_{7}=2.448279 \mathrm{e}-24 \mathrm{~m}^{-6} \mathrm{~s}^{-1} \\
& \mathrm{~b}(\mathrm{z})=c_{1}+c_{2} z+c_{3} z^{2}+c_{4} z^{3}+c_{5} z^{4}+c_{6} z^{5}
\end{aligned}
$$

where:

$$
\begin{aligned}
& c_{1}=-.0179545 \mathrm{~s}^{-1} \\
& c_{2}=3.9960830 \mathrm{e}-05 \mathrm{~m}^{-1} \mathrm{~s}^{-1} \\
& c_{3}=-1.243271 \mathrm{e}-08 \mathrm{~m}^{-2} \mathrm{~s}^{-1} \\
& c_{4}=1.760674 \mathrm{e}-12 \mathrm{~m}^{-3} \mathrm{~s}^{-1} \\
& c_{5}=-1.153713 \mathrm{e}-16 \mathrm{~m}^{-4} \mathrm{~s}^{-1} \\
& c_{6}=2.807013 \mathrm{e}-21 \mathrm{~m}^{-5} \mathrm{~s}^{-1}
\end{aligned}
$$

$$
\begin{array}{ll}
V_{n}(z)=232.21 \mathrm{~ms}^{-1} & \text { for } z>9.1 \mathrm{~km} \\
V_{n}(z)=c_{1}+c_{2} z+c_{3} z^{2} & \text { for } 3.0 \mathrm{~km} \leq z \leq 9.1 \mathrm{~km}
\end{array}
$$

where:

$$
\begin{aligned}
& c_{1}=150.1493 \mathrm{~m} \mathrm{~s}^{-1} \\
& c_{2}=6.2023 \mathrm{e}-3 \mathrm{~s}^{-1} \\
& c_{3}=3.0298 \mathrm{e}-7 \mathrm{~m}^{-1} \mathrm{~s}^{-1}
\end{aligned}
$$

The accuracy of Eq. (3) has been verified from NASA B757 in situ flight data.

\section{$\underline{0^{\text {th }} \text {-Order Aircraft Dynamic Model }}$}

A second relationship for estimating $\sigma_{\Delta \mathrm{n}}$ is proposed that is much simpler to apply than higher-order, timedomain aircraft flight dynamics models. The proposed relationship is applied to a particular flight path of choice estimating the loads based on the vertical winds and is designed to provide an aircraft load estimate as a check against other techniques. The relationship has been verified with NASA B757 in situ data and is applied to the simulation results presented above.

First, $\Delta n$ is calculated from the horizontal gradient of vertical velocity along a specified flight path; i.e., :

$$
\Delta n=\frac{V_{a}}{g} \frac{\partial \bar{w}}{\partial l} k
$$

where the running mean of $w$ is calculated along a flight path $l$ as:

$$
\bar{w}(l)=\frac{1}{L_{l}} \int_{l-\frac{L_{l}}{2}}^{l+\frac{L_{l}}{2}} w\left(l^{\prime}\right) d l^{\prime}
$$

$V_{a}$ is the aircraft's airspeed, the averaging interval, $L_{l}=$ $300 \mathrm{~m}$, and $k$ is a constant determined by aircraft type and weight. The estimate of $\sigma_{\Delta \mathrm{n}}$ is then calculated from $\Delta \mathrm{n}$ assuming a $5 \mathrm{~s}(\sim 1 \mathrm{~km})$ running window.

Optimization of the $0^{\text {th }}$-order model is still being investigated, but initial results support the constant, $k=$ 0.69 for the NASA B757.

Prior to comparing the two hazard models to the three simulated cases, estimated loads from the $0^{\text {th }}$-order model are compared to observed loads from NASA B757 in situ data. Figure 15 and Figure 16 show comparisons for each of the two flight events, 235_05 and 232_10, respectively. The actual events compare well with the loads predicted by the $0^{\text {th }}$-order model.

For application in the simulated wind fields, the $0^{\text {th }}$ order model is calculated for flight paths through each grid point that are parallel to either the $X$ - or $Y$-coordinate axes. Flight paths for 235_05 are calculated along the $X$ - 
coordinate, while flight paths for 232_10 and the FOQA case are calculated along the $Y$-coordinate. These headings correspond with the actual aircraft headings during each event.

Figure 17-Figure 22 present the hazard analyses for all three events. The distributions of estimated RMS normal loads compare well between each of the two hazard models. Similarly, the estimated loads compare well with the measured loads from in situ (Table 4).

Analyses of the numerical data sets show that peak loads from the hazard estimation models (Figure 17Figure 22) are not necessarily correlated with regions of peak radar reflectivity (Figure 6, Figure 10, and Figure 13). Furthermore, high turbulence intensities can occur outside of regions of significant radar reflectivity.

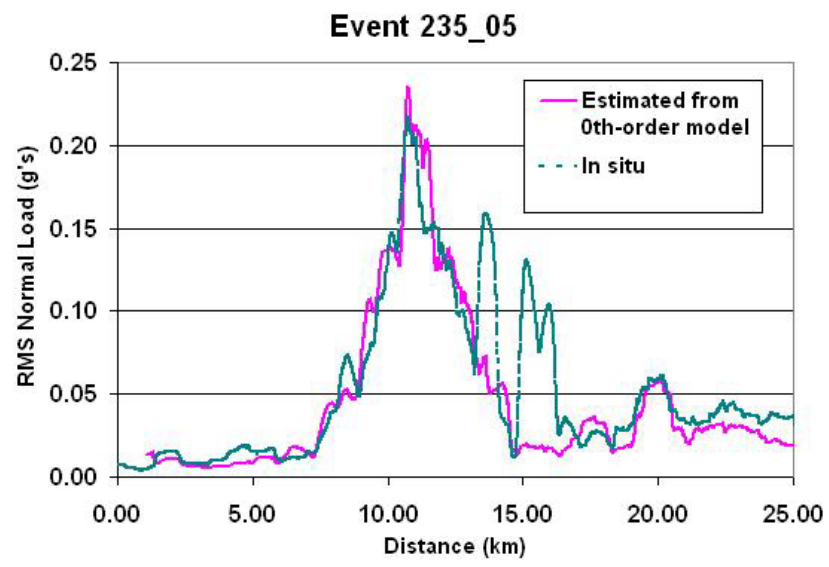

Figure 15. Estimated and observed $\sigma_{\Delta n}$ Event 235_05.

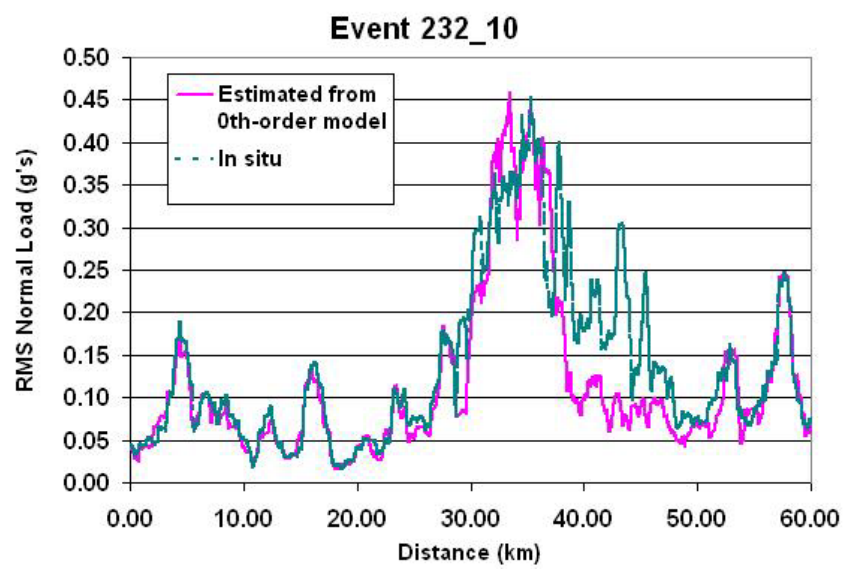

Figure 16. Same as in Figure 15, but for Event 232-10.

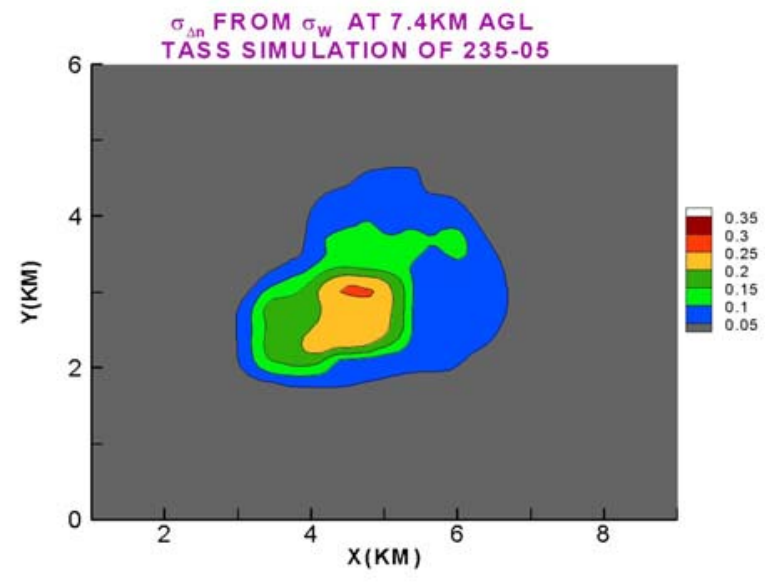

Figure 17. Horizontal cross section of $\sigma_{\Delta n}$ field ( $g$ 's) from the Hazard Estimation Model for the simulated Event 235_05.

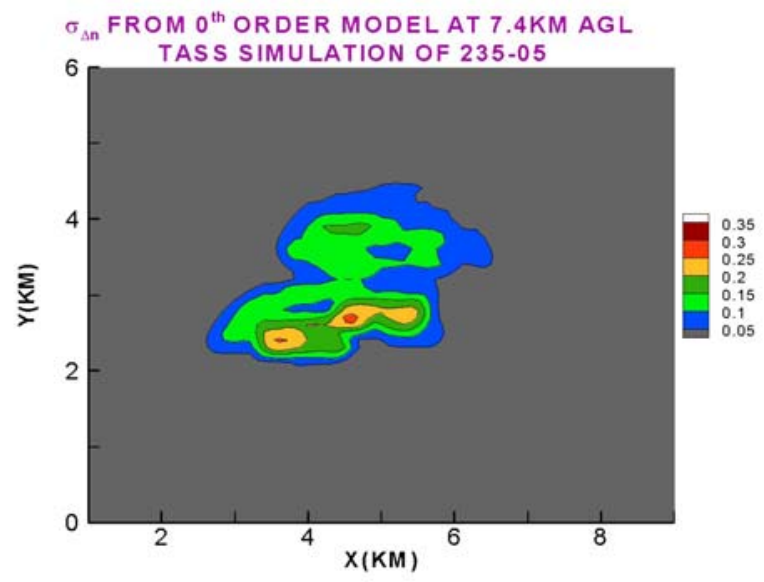

Figure 18. Horizontal cross section of $\sigma_{\Delta n}$ field ( $g$ 's) from the $0^{\text {th }}$-order aircraft performance model for simulated Event 235_05.

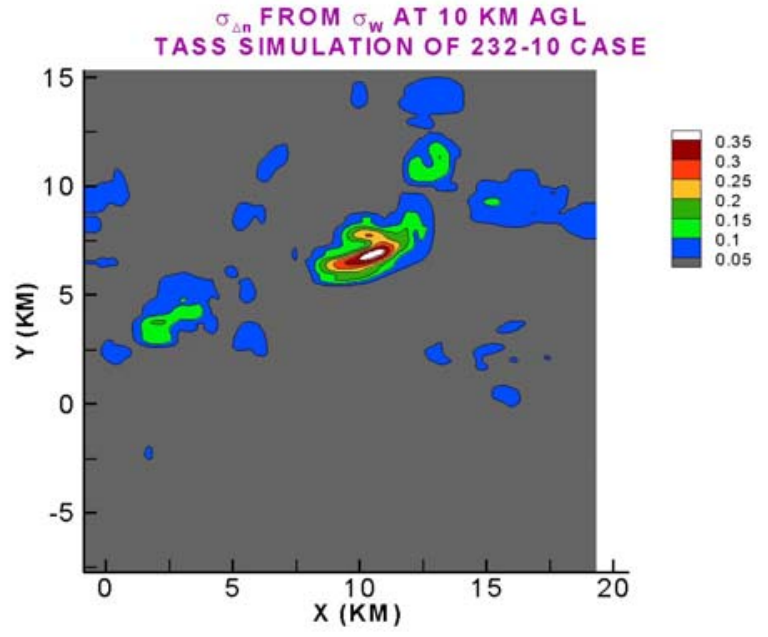

Figure 19. Same as Figure 17, but for Event 232_10. 


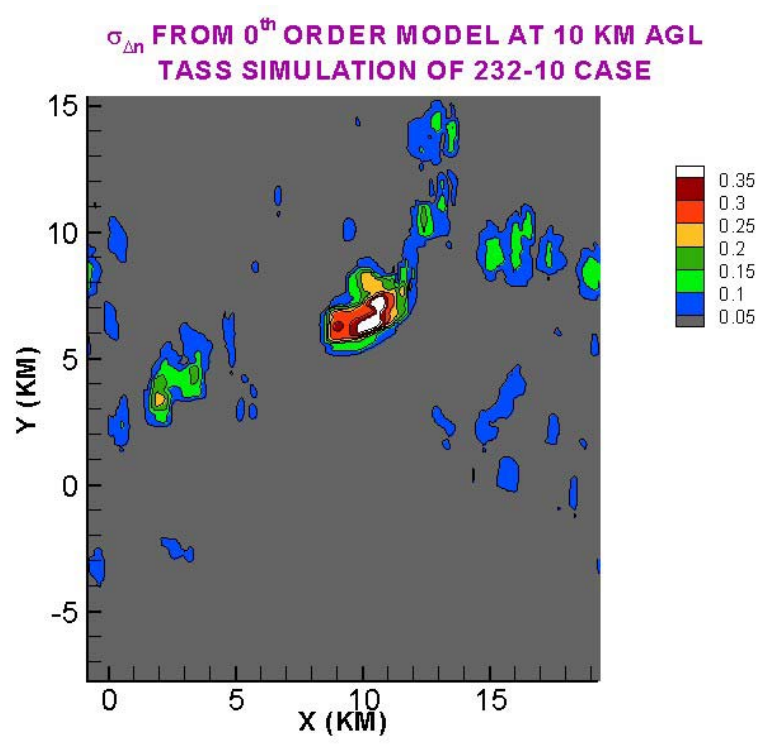

Figure 20. Same as Figure 18, but for Event 232_10.

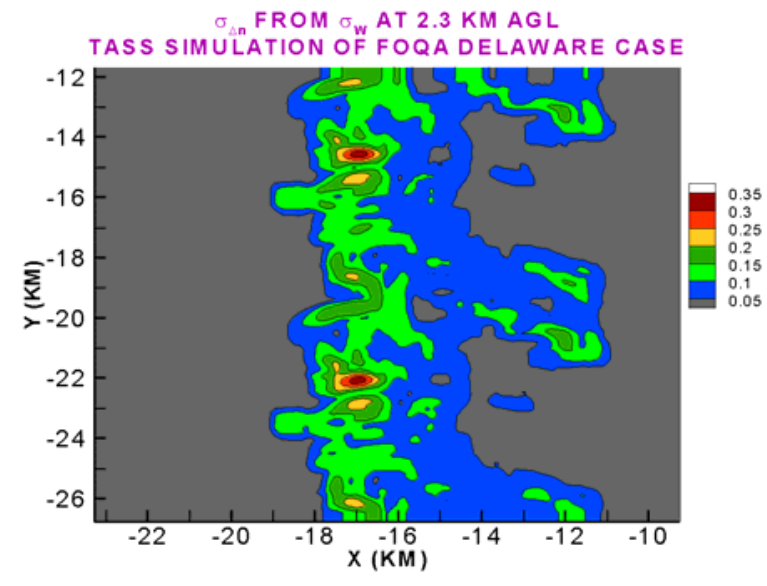

Figure 21. Same as in Figure 17, but for FOQA case.

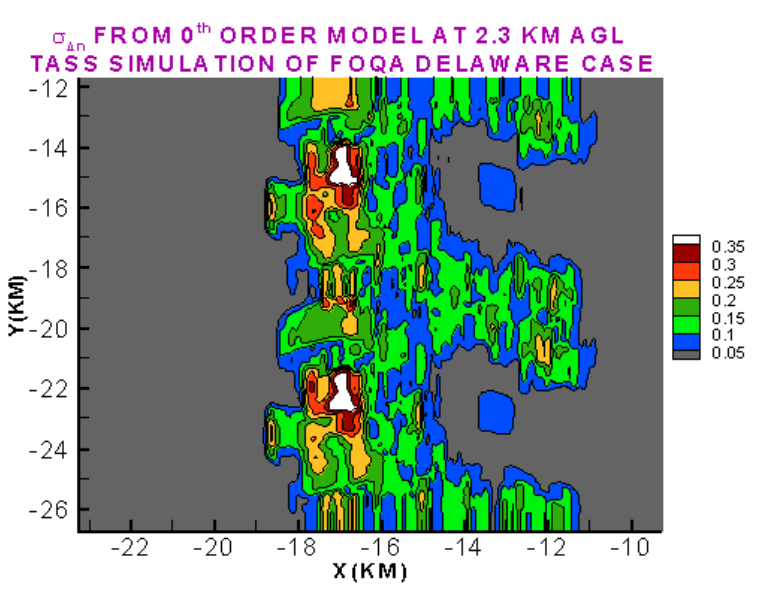

Figure 22. Same as in Figure 18, but for FOQA case.

\section{Summary}

Three cases of aircraft encounters with convectively induced turbulence have been presented. Large eddy simulations were conducted for each of the convective systems responsible for the turbulence and their results compare well with observations. Two hazard metric models have been introduced and validated with aircraft in situ data. The models' predicted loads compare reasonably well with the observed aircraft loads. The LES data sets and hazard metric models can be useful tools for characterizing CIT turbulence and evaluating turbulence detection sensors.

\section{$\underline{\text { Acknowledgements }}$}

This research was sponsored by NASA's Aviation Safety Program. The authors would like to thank Roland Bowles of AeroTech Research, Inc for his contributions to this paper.

Table 4. Comparisons between observed and modeled $\sigma_{\Delta \mathrm{n}}$ for each of the three cases.

\begin{tabular}{|c|c|c|c|}
\hline \multirow{2}{*}{ Source } & \multicolumn{3}{|c|}{ Peak $\sigma_{\Delta \mathrm{n}}(\mathrm{g}$ 's) } \\
\hline & Event 235_05 & Event 232_10 & FOQA Case \\
\hline In situ & 0.22 & 0.45 & 0.37 \\
\hline Hazard Estimation Model $\left(\sigma_{\mathrm{w}}\right)$ & 0.26 & 0.38 & 0.33 \\
\hline $0^{\text {th }}$-Order Aircraft Perf. Model & 0.27 & 0.43 & 0.45 \\
\hline
\end{tabular}

\section{References}

${ }^{1}$ Hamilton, D.W., and Proctor, F.H., "Meteorology Associated with Turbulence Encounters During NASA's Fall-2000 Flight Experiments," $40^{\text {th }}$ Aerospace Sciences
Meeting and Exhibit, AIAA-2002-0943, Reno, NV, January 2002, 11pp.

${ }^{2}$ Proctor, F.H., Hamilton, D.W., and Bowles, R.L., "Numerical Study of a Convective Turbulence 
Encounter," 40 ${ }^{\text {th }}$ Aerospace Sciences Meeting and Exhibit, AIAA-2002-0944, Reno, NV, January 2002, $14 \mathrm{pp}$.

${ }^{3}$ Hamilton, D.W., and Proctor, F.H., "Convectively Induced Turbulence Encounters During NASA's Fall 2000 Flight Experiments," Preprints, $10^{\text {th }}$ Conference on Aviation, Range, and Aerospace Meteorology, Portland, OR, Amer. Meteor. Soc., May 2002, pp. 371-374.

${ }^{4}$ Proctor, F.H., Hamilton, D.W., and Bowles, R. L., "Numerical Simulation of a Convective Turbulence Event," Preprints, $10^{\text {th }}$ Conference on Aviation, Range, and Aerospace Meteorology, Portland, OR, Amer. Meteor. Soc., May 2002, pp. 41-44.

${ }^{5}$ Kaplan, M.L., Huffman, A. W., Lux, K. M., Charney, J.J., Riordan, A.J., and Lin, Y.-L., "Characterizing the Severe Turbulence Environments Associated With Commercial Aviation Accidents---Part I: 44 Case Study Synoptic Observational Analyses," NASA/CR-2002-211918, August 2002, 57 pp.

${ }^{6}$ Bowles, R.L., Hamilton, D.W., and Cornman, L., "FY02 TPAWS Radar NASA B757 Flight Campaign Summary," Presentation from proceedings, NASA's $3^{\text {rd }}$ Annual Weather Accident Prevention Review, Lexington, MA, NASA, 20-21 November 2002.

${ }^{7}$ Polger, P.D., Goldsmith, B.S., Przywarty, R.C. and Bocchieri, J.R., "National Weather Service warning performance based on the WSR-88D," Bulletin of the American Meteorological Society, Vol. 75,1994, pp. 203214.

${ }^{8}$ Benjamin, S.G., Weygandt, S.S., Schwartz, B.E., Smith, T.L., Smirnova, T.G., Kim, D., Grell, G., Devenyi, D., Brundage, K.J., Brown, J.M., and Manikin, G.S., "The 20-km RUC in operations," Preprints, 15th Conf. on Numerical Weather Prediction, San Antonio, TX, Amer. Meteor. Soc., 2002, pp. 379-382.

9 Ferris, R.F, "Meteorological Case Studies of Turbulence Encounters," Presentation from proceedings, NASA's $2^{\text {nd }}$ Annual Weather Accident Prevention Annual Review, Cleveland, OH, NASA, 5-7 June 2001.

${ }_{10}$ MESO, 1994: MASS Version 5.6 Reference Manual, MESO, Inc., 185 Jordan Rd., Troy, NY 12180, $118 \mathrm{pp}$.

${ }^{11}$ Bowles, R.L., "Aircraft Centered Hazard Metric Based on Airborne Radar Turbulence Observables," AeroTech Report ATR-12010, (prepared for NASA Langley Research Center), September 2000. 